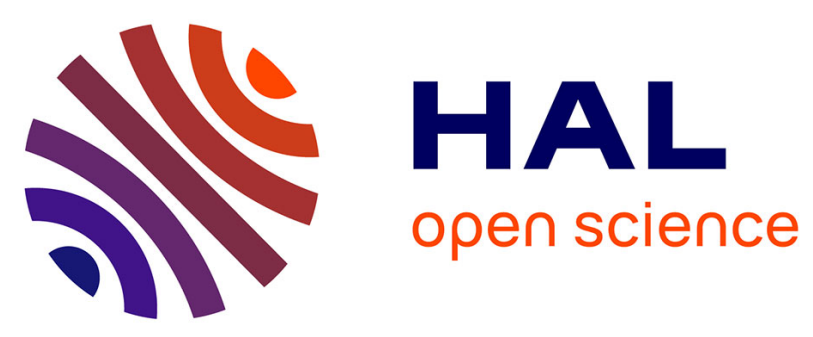

\title{
Self-assembled InAs quantum dots grown on InP (3 1 1)B substrates: Role of buffer layer and amount of InAs deposited
}

\author{
Ibrahim Alghoraibi, Tony Rohel, Nicolas Bertru, Alain Le Corre, Antoine \\ Letoublon, Philippe Caroff, Olivier Dehaese, Slimane Loualiche
}

\section{To cite this version:}

Ibrahim Alghoraibi, Tony Rohel, Nicolas Bertru, Alain Le Corre, Antoine Letoublon, et al.. Selfassembled InAs quantum dots grown on InP ( $\left.\begin{array}{lll}3 & 1 & 1\end{array}\right)$ B substrates: Role of buffer layer and amount of InAs deposited. Journal of Crystal Growth, 2006, 293, pp.263. 10.1016/j.jcrysgro.2006.05.046 . hal-00485589

\section{HAL Id: hal-00485589 \\ https://hal.science/hal-00485589}

Submitted on 21 May 2010

HAL is a multi-disciplinary open access archive for the deposit and dissemination of scientific research documents, whether they are published or not. The documents may come from teaching and research institutions in France or abroad, or from public or private research centers.
L'archive ouverte pluridisciplinaire HAL, est destinée au dépôt et à la diffusion de documents scientifiques de niveau recherche, publiés ou non, émanant des établissements d'enseignement et de recherche français ou étrangers, des laboratoires publics ou privés. 
Self-assembled InAs quantum dots grown on $\operatorname{InP}(311) \mathrm{B}$ substrates: Role of buffer layer and amount of $\operatorname{InAs}$ deposited

\author{
Ibrahim Alghoraibi, Tony Rohel, Nicolas Bertru, Alain Le Corre ...
}

\title{
UMR C6082 FOTON
}

INSA- Rennes, 20 avenue des buttes de Coesmes, F-35043 Rennes Cedex, France

\section{Abstract}

The formation of InAs quantum dots by Stransky-Krastanow method on (311) B InP substrates has been studied. On $\mathrm{Al}_{0.48} \mathrm{In}_{0.52} \mathrm{As}$ alloy lattice matched on InP, large changes of the quantum dot structural characteristics were observed as a function of the amount of InAs deposited and of the As pressure during the InAs quantum dots formation. Small quantum dots (minimum diameter $=20 \mathrm{~nm}$ ) in very high density $\left(1.3 \times 10^{11}\right.$ quantum dots per $\left.\mathrm{cm}^{2}\right)$ were achieved in optimized growth conditions. These results are interpreted from the strong strain field interaction though the substrate at high density and from the InAs surface energy evolutions with the As pressure. The effect on quantum dot characteristics of the arsenic pressure during the growth of $\mathrm{Al}_{0.48} \mathrm{In}_{0.52} \mathrm{As}$ buffer layers has been also investigated. Despite the importance of this parameter on the $\mathrm{Al}_{0.48} \mathrm{In}_{0.52} \mathrm{As}$ clustering, weak changes on quantum dots were observed.

Keywords: Molecular beam epitaxy (MBE), self-assembled quantum dots (QDs), nanostructures, growth conditions, high density, InAs,/InAIAs,/InP(311)B. 


\section{Introduction}

Quantum dot (QD) structures elaborated by Stranki-Krastanov (SK) method have demonstrated a large potential in optoelectronic devices [1]. Considerable efforts have been devoted to understand and to control the formation of InAs QDs on GaAs substrates. Devices with some of the improved performances predicted for QD such QD laser with very low threshold current density have been reported in this material system. [2,3] However (In,Ga)As/GaAs QDs emitting at wavelength longer than 1.4 $\mu \mathrm{m}$ with a good optical efficiency appear today difficult to achieve [4]. InAs QDs grown on InP substrates have been proposed for longer wavelength emission [5]. They can emit at wavelengths around $1.55 \mu \mathrm{m}$ which correspond to the minimum of optical fiber absorption and which are widely used in long haul optical telecom. However, between the InAs and InP lattices, the mismatch is the half of the lattice mismatch existing between InAs and GaAs and the InAs nanostructure formation is drastically changed. For example, the deposit of few monolayers (ML) of InAs on InP (100) surfaces by molecular beam epitaxy (MBE) leads to the formation of modulated quantum wells, quantum wires or quantum dash as a function of growth conditions or more subtle changes such as buffer layer growth method [6-8]. Many studies have been performed on the effect of growth conditions on the nanostructures formed on InP (100). Few authors have pointed out the major role played by the buffer layer nature on the QD structural properties. Despite these efforts up to now, QDs in high density with large separation between electronic levels have been not achieved by MBE on InP (100) substrates.

Deposition on high index surfaces such as (311)B allow the formation of a high density of small QDs on InP substrates [9]. Already, devices with improved performance have been achieved on such substrates [10,11]. However, the effect of the growth conditions on the QD size and QD density have been not yet extensively investigated on the high index InP substrate. Especially, extensive study on the formation of QDs on (Al,Ga,In)As alloys lattice matched on InP has been not reported. In this paper the structural characteristic evolutions induced by the composition of the alloy buffer layer, by the amount of InAs deposited, and by the As Pressure have been studied. 


\section{Experimental procedure}

The samples under investigation were grown by solid source MBE in a compact 21 Riber system on (311)B InP substrates. After oxide adsorption at $530{ }^{\circ} \mathrm{C}$ under phosphorus flux, a $0.5 \mu \mathrm{m}$ thick InP buffer layer, followed by a $0.25 \mu \mathrm{m}$ thick AlGalnAs buffer layers lattice matched to InP were grown. During the growth of AlGalnAs alloys the substrate temperature was set at $500^{\circ} \mathrm{C}$ and the Beam Equivalent Pressure (BEP) was fixed at $5.10^{-6}$ Torr. The latticematch conditions were checked in advance by $X$ ray diffraction measurements. The composition of the AlGalnAs alloy layers were either $\left.A\right|_{0.48} I_{0.52} A s, G a_{0.47} I_{0.53} A s$ or $A l_{0.29} G a_{0.19} \mid n_{0.52} A s$ according to the samples. The InAs QDs were formed by deposition of various amount of $\operatorname{InAs}$ at $0.17 \mathrm{ML} / \mathrm{s}$ at $480^{\circ} \mathrm{C}$. The amount of InAs is given in (100) equivalent ML. Due to the higher atom surface density on (100) than on (311)B surface, the deposit of one monolayer on (100) surface corresponds to the formation of 1.65 monolayer on (311)B. After the island formation, a 10s growth interrupt under As flux was performed for all the samples. Then the samples to be imaged by Atomic force microscopy (AFM) were cooled down quickly to room temperature. The AFM measurement were performed in contact mode.

\section{Results and discussion}

On Fig. 1 are reported AFM images recorded on samples on which $2.5 \mathrm{ML}$ of InAs have been deposited on $\mathrm{Al}_{0.48} \mathrm{In}_{0.52} \mathrm{As}$, on $\mathrm{Al}_{0.29} \mathrm{Ga}_{0.19} \mid \mathrm{n}_{0.52} \mathrm{As}$, and on $\mathrm{Ga}_{0.47} \mathrm{In}_{0.53}$ As surfaces. The island diameter $(d)$ becomes smaller and the density (dens) increases with the Al content, e.g. $d \approx 23 \mathrm{~nm}$ and dens $\approx 7.510^{10} \mathrm{Is} / \mathrm{cm}^{2}$ on $\mathrm{Al}_{0.48} \mathrm{In}_{0.52} \mathrm{As}$ whereas $d \approx 47 \mathrm{~nm}$ and dens $\approx 2.510^{10} \mathrm{Is} / \mathrm{cm}^{2}$ on $\mathrm{Ga}_{0.47} \mathrm{In}_{0.52} \mathrm{As}$. The islands formed on $\mathrm{Al}_{0.29} \mathrm{Ga}_{0.19} \mathrm{In}_{0.52} \mathrm{As}$ present intermediate values of size and density $\left(d \approx 28 \mathrm{~nm}\right.$ and dens $\left.\approx 6.5 \times 10^{10} \mathrm{Is} / \mathrm{cm}^{2}\right)$. Thus smaller islands in higher density is obtained for Al rich surface. Similar trends have been reported for InAs QDs formed on AIGaAs and AlGalnAs alloys lattice-matched on $\mathrm{GaAs}(100)$ and InP (100) substrates respectively $[7,12]$. It has been related to lower In diffusion on Al rich surface which favours the formation of smaller island in higher density on Al rich surface. 
Smaller islands present higher electronic confinement effect and therefore should present a more like QD behaviour. Therefore, in the following we focus our study on islands formed on AllnAs. AFM images for various amount of InAs deposited on AllnAs are shown in Fig. 2(a-c) and results from statistical treatments of the images are reported in Fig. 2(d). The QD density increases continuously with the amount of InAs deposited. It reaches $1.3 \times 10^{11}$ islands $/ \mathrm{cm}^{2}$ for $3.5 \mathrm{ML} \operatorname{InAs}$ deposited. Diameters follow an opposite evolution. The islands become smaller for larger InAs deposit. The smallest islands, obtained by 3.5 ML deposition have diameter as small as $20 \mathrm{~nm}$. The size fluctuation of the QDs is also reduced for large amount of InAs deposited, the diameter fluctuation $\Delta d / d$ for example is $45 \%$ for 2.5 $M L$ deposit and $31 \%$ for $3.5 \mathrm{ML}$ deposit.

Such evolution can be related to interacting stress field induced by the QD within the substrates. Such effect has been already reported for GalnAs QD formed on (311)B GaAs [13] and InAs islands formed on InP [5]. A part of the stress accumulated by the QDs is released within the substrate. At high density, when the distance between the QD is in the same order than the islands diameter, the stress fields within the substrate interact leading to a reduction of the island size and of the size fluctuation.

To go further we calculate the InAs volume as a function of the amount of InAs deposited. The average QD volume was determined by directly integrating AFM images using image processing software with no assumption made about the actual shape of the dots. Fig. 3 is a plot of the total volume of the dots. The solid lines represent the predicted total QD volume by a classic Stranski-Krastanow (SK) mechanism with various critical thickness. The slope of theses curves agree roughly with the experimental QD volume. In the other words. The volume of InAs deposited beyond 2.5 ML corresponds to the QD volume increase as predicted in classic Stranski-Krastanow growth mode. The critical thickness is roughly determined by this mean to be $1 \mathrm{ML}$. It correspond to the formation of around. The critical thickness determined by RHEED experiments for InAs deposition on $\mathrm{Ga}_{0.47} \mathrm{In}_{0.53}$ As (311)B surface is 0.95 monolayer (e.g 1.6 atomic planes in the [311]B) [14]. However the critical thickness appears quite small for the low lattice mismatch $(3 \%)$ existing between $\operatorname{InP}$ and InAs. [15] We assume that it is related to large In segregation during the AllnAs growth which lead high Indium concentration on surface before Indium cell opening. 
Finally we studied the effect of the As flux during the QD formation. Firstly, we studied the effect of the As pressure during the QD formation. On Fig. 4, AFM images from samples grown with a high As pressure (BEP : $1.5 \times 10^{-5}$ torr) and low As pressure ( BEP $1.5 \times 10^{-6}$ torr) are shown. For both condition the surface reconstruction corresponds to As rich surface. The InAs deposit and the BEP during the AllnAs alloy growth were set at $3 \mathrm{ML}$ and $1.510^{-5}$ torr respectively. The QDs grown with high As pressure have an average height of $3.4 \mathrm{~nm}$, a mean radius of $30.4 \mathrm{~nm}$ and an area density of $5.5 \times 10^{10}$ islands $/ \mathrm{cm}^{2}$. When decreasing As pressure, the mean QD height and radius are reduced to 2.2 and $23.8 \mathrm{~nm}$ respectively. The area density is roughly twice and reach $1.2 \times 10^{11}$ islands $/ \mathrm{cm}^{2}$. Therefore, as reported previously for QDs formed on GalnAsP alloys, a drastic reduction of size and density increase is observed when the As BEP is reduced [16]. The mechanism at the origin of the size reduction is still unclear. For InAs QDs formed on (100) GaAs surface an increase of the island size is observed for lower arsenic pressure. This trend has been related to indium diffusion length changes when varying the arsenic pressures. Evidently such explanation can not interpret our results. Because same trends are observed on (311)B surface for deposits on AIGalnAs or GalnAsP surface, it seems not specific to the buffer nature or to the alloy surface roughness. A possible explanation is the increase of the InAs (311)B surface energy for low As pressure. A larger instability at low arsenic pressure should favor QD nucleation and leads to high density of small QDs apart from buffer layer as observed.

During the previous experiments, the As pressure during the AllnAs buffer layer growth was set at $1.5 \times 10^{-5}$ torr. Indeed number of studies have shown that due to the large difference between In- and Al- related bond energy, the AllnAs alloy can present clustering and phase separation. The clustering depends of the growth conditions ( e.g substrate temperature, growth rate and As BEP). Usually it is reported that moderate temperature and high As BEP are required to reduce AllnAs clustering. Cluster or surface roughness of the alloy surface on which QDs will be formed should induce size and density fluctuation. To check the importance of this effects we deposited $3 \mathrm{ML}$ of InAs in standard conditions on AllnAs buffer layer grown with different As pressure. The density and diameter determinated by AFM as a function of the As BEP are reported on Fig. 5. 
Weak evolutions are observed as a function of arsenic BEP during the AllnAs growth. The density change for extrema value from $x x$ to and the diameter from $x x$ to $x x$. Therefore, at the contrary to nanostructures formed on $\operatorname{InP}(100)$, the QDs formed on AllnAs (311)B appears robust to buffer layer quality. It is crucial for use them for devices fabrication.

\section{Conclusion}

The formation of InAs QDs on AIGalnAs alloys lattice matched on InP (311)B substrates have been investigated. Decrease of the QD size and Increase of the QD density were observed as a function of the amount of InAs deposited. Small quantum dots (minimum diameter $=20 \mathrm{~nm})$ in very high density $\left(1.3 \times 10^{11}\right.$ quantum dots per

$\mathrm{cm}^{2}$ ) were achieved in optimized growth conditions. Moreover, the evolution of the island volume have shown that far behind the SK transition, all the indium deposited are incorporated within the QDs. The critical thickness of 1.65 (311) planes was determined. We assume that such small value is related to the indium floating layer existing at the top of the AllnAs buffer layer due to the segregation phenomenon. Changes of the As pressure during the QDs formation result in drastic evolution of the QDs density and size. At the contrary, the As pressure during the growth of the buffer layer seems to have, in the range of BEP studied, only small effects on the QD formation. In conclusion the control of the QD growth parameter provides straightforward means to tailor the size and density on QDs grown on AIGalnAs alloy lattice matched on InP.

The authors are grateful to P. Caroff for helpful discussion about AFM imaging. The authors would also like to thank T. Rohel for technical support. This work is supported by European Networks of Excellence Sandie and by Region Bretagne. 


\section{References}

[1 D. Bimberg, M. Grundmann, N. N. Ledentsov, Quantum Dot Heterostructures, Wiley, Chichester, New York 1999.

[2] M. Grundmann, Physica E (Amsterdam) 5 (2000) 167.

[3] Y. Masumoto, T. Takagahara (Eds), Semiconductor Quantum Dots Springer, Berlin, Heidelberg 2002

[4 grand longueur d'onde crystal growth

[5] A. Ponchet, A. Le Corre, H. L'Haridon, B. Lambert, and S. Salaün, Appl. Phys. Lett. 67 (1995) 1850.

[6] N. Lebouché-Girard, A. Rudra and E. Kapon, J. Crystal. Growth 175-176, (1997) 1210.

[7] J. Brault, M. Gendry, G. Grenet, G. Holinger, Y. Desieres, and T. Benyattou, Appl. Phys. Lett. 73, (1998)2932.

[8] L. Gonzalez, J. M. Garcia, R. Garcia, F. Briones, J. M. Pastor, and C. Ballesteros, Appl. Phys. Lett. 76 (2000) 1104.

[9] S. Frechengues, V. Drouot, N. Bertru, B. Lambert, S. Loualiche, A. Le Corre, J. Crystal. Growth 201/202 (1999) 1180

[10] H. Saito, K. Nishi, and S. Sugou, Appl. Phys. Lett. 78, (2001) 267.

[11] P. Caroff, C. Paranthoen,_ C. Platz, O. Dehaese, H. Folliot, N. Bertru, C. Labbé, R. Piron, E. Homeyer, A. Le Corre, and S. Loualiche, Appl. Phys. Lett. 87, (2005) 243107.

[12] ilots sur algaas

[13] H. Zu, K. Akahane, H. Z. Song, Y. Okada, and M. Kawabe, J. Crystal. Growth 234, (2002) 509.

[14] these caroff ou a publi

[15] A. polimeni, A. Patane, M. Henini, L. Eaves, P. C . Main, S. Sanguinetti, M. Guzzi, J. Crystal. Growth 201/202 (1999) 276.

[16] P. Caroff, N. Bertru, A. Le Corre, O. Dehaese, T. Rohel, I. Alghoraibi, H. Folliot and S. Loualiche, Jpn. J. Appl. Phys. 44 (2005) L 1069. 


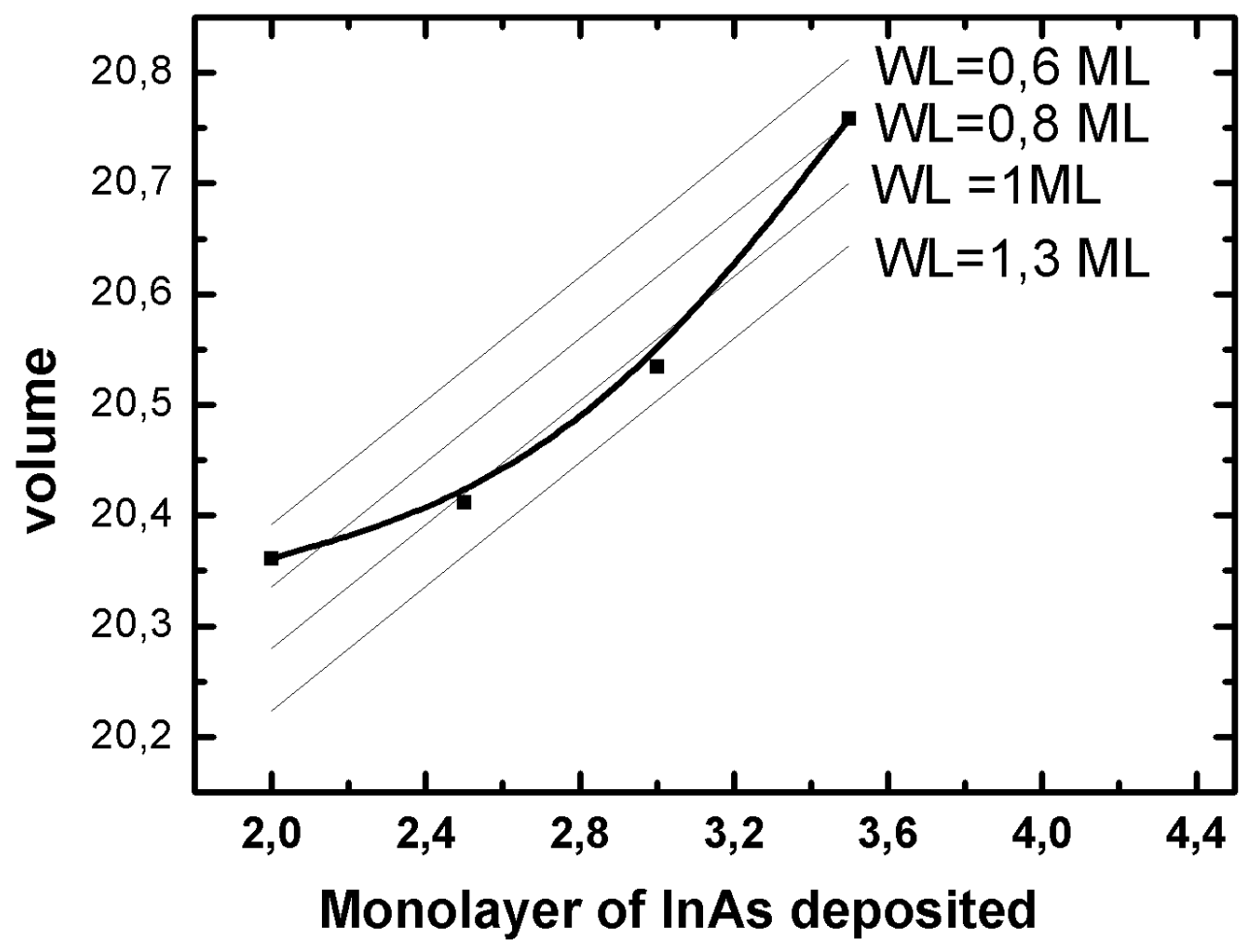

